\title{
A STUDY OF PRINCIPLE STRESS ROTATION ON GRANULAR SOILS USING DEM SIMULATION OF HOLLOW CYLINDER TEST
}

\author{
B. FARHANG ${ }^{1}$, A. A. MIRGHASEMI² \\ ${ }^{1}$ Benyamin Farhang, Ph.D. Candidate of Soil Mechanics and Foundation Engineering \\ School of Civil Engineering, College of Engineering, University of Tehran, Tehran, Iran \\ E-mail: b.farhang@ut.ac.ir \\ ${ }^{2(\bowtie)}$ Ali Asghar Mirghasemi, Professor of Soil Mechanics and Foundation Engineering \\ School of Civil Engineering, College of Engineering, University of Tehran, Tehran, Iran \\ E-mail: aghasemi@ut.ac.ir
}

Key words: Discrete element method, Granular soils, Hollow cylinder apparatus, principal stress rotation.

\begin{abstract}
This study presents a numerical modelling of HCT (Hollow Cylinder Test) using DEM (Discrete Element Method) by developing of TRUBAL code on granular soils. Due to high expenditures of HCT, a verified numerical modelling of this test was developed. In addition, this numerical model can be used to address the gap in understanding the relationship between the particle-scale interactions and the overall material response. In the introduced numerical model (HCTBALL), plane and cylindrical walls were defined to apply the boundary forces and stresses. Also, an efficient method was presented to apply the torque. The displacements of inner and outer walls were interdependent while applying the torsion to control the intermediate principal stress parameter (b). To verify the model, the results of experimental hollow cylinder tests on Firoozkooh sand under monotonic loading and drained condition were employed. Therefore, the simulations were compared qualitatively with experiments to verify the presented model. It is observed that the deviatoric stress at failure, increased with a decreasing rate by increasing the confining pressure. By increasing the rotation angle of principal stress direction, the difference between deviatoric stresses in specific confining pressures was decreased.
\end{abstract}

\section{INTRODUCTION}

This paper presents a numerical modelling of HCT using DEM by developing of TRUBAL code (Cundall, 1989 - Aston Version) on granular soils under monotonic loading and drained condition.

Soils, usually show anisotropic behavior that depends on their structure (inherent and induced formation history) and environmental factors. These environmental factors (seismic loads, traffic, sea waves and etc.) cause principal stress rotation which plays an important role in soils behaviour and ignoring this factor may cause an insecure design of geotechnical structures. The hollow cylinder apparatus is a versatile testing device widely employed to investigate the constitutive behavior of soils under generalized stress conditions, including principal stress rotation, anisotropy and non-coaxiality [1,2]. Saada et al. [3, 4] pioneered the 
use of HCA for investigating the effects of principal stress rotation in sands and clays. Several theoretical and experimental research have been carried out on the rotation of principal stress directions and its importance in soil response by researchers [1, 2, 5-7]. The HCA is able to apply a torsion and therefore a shear stress in the soil sample which results in the principal stress axis rotations.

Regarding all the capabilities, with HCT and all the other experimental tests, the micromechanical parameters of soils cannot be investigated and there could be some limitations to change the testing conditions quickly and effortlessly. DEM can solve this problems and could be used as a virtual laboratory to fill the gap in understanding the relationship between the particle-scale interactions and the overall material response. It is a numerical tool that can be used to address this gap, because the particle-scale interactions which cannot be measured in laboratory tests, can easily be monitored in "virtual" tests [8]. This method firstly used by Cundall [9] to simulate progressive large-scale movements in blocky rock systems. BALL was extended to an early version of TRUBAL by Cundall and Strack that used linear spring contact laws. Cundall extended the above early version of TRUBAL [10]. In this version, nonlinear contact laws are used.

Thereafter, various research were carried out to develop the TRUBAL code for different studies. Dorostkar and Mirghasemi [11] extended the TRUBAL code to calculate the anisotropy parameters of particles in micro scale. Recently, numerical simulations of hollow cylinder test have been carried out using PFC3D software by Li, et al. to investigate the propagation of shear band in granular soils $[12,13]$. In the current study, the three-dimensional simulation of the HCT was done by developing TRUBAL code to investigate the shear strength parameters of granular soils with the ability to control the intermediate principle stress parameter $b$. This parameter plays an important role in the behavior of soils. Numerical simulations were carried out with drained and monotonic loading conditions. To verify the presented numerical simulation, the results of experimental drained hollow cylinder tests on Firoozkooh sand under monotonic loading conditions [14] were used.
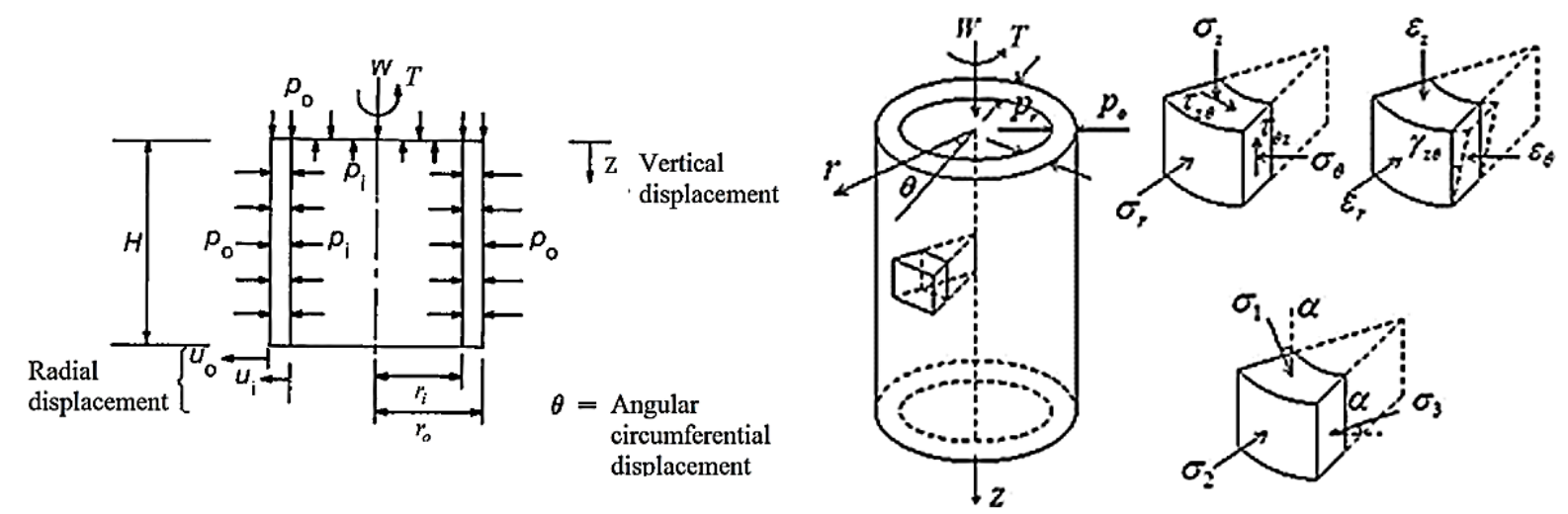

Figure 1: Forces acting on the hollow cylinder specimen $[7,12]$

\section{HOLLOW CYLINDER TEST}

The HCA, allows independent control of the magnitudes of principal stresses and their directions $(\alpha)$. Figure 1 shows the idealized stress condition in a hollow cylindrical element subjected to the axial load $(\mathrm{W})$, torque $(\mathrm{T})$, internal pressure $\left(\mathrm{P}_{\mathrm{i}}\right)$ and external cell pressure $\left(\mathrm{P}_{\mathrm{o}}\right)$. 
During shearing, the torque (T) applies shear stresses $\left(\tau_{\theta z}=\tau_{z \theta}\right)$ in the horizontal plane of the sample. The axial load (W), applies the vertical stress ( $\sigma \mathrm{z})$, and Pi and Po control the radial and circumferential stresses $\left(\sigma_{\mathrm{r}}\right.$ and $\left.\sigma_{\theta}\right)$. Hight et al. [7] proposed equations for the average stress and strain calculations for the HCA. These are the same as those in Yang et al. [15].

\section{SIMULATION USING DEM}

In this study, the three-dimensional simulation of the HCT was done by developing the ASTON version of TRUBAL code named GRANULAR (Derived from Cundall's DEM Code Trubal Version 1.51: 9 May 1989) to investigate the mechanical behavior of granular soils with the ability to control the intermediate principle stress parameter $b$. Numerical simulations were carried out with drained and monotonic loading conditions.

To calculate the particle-particle and particle-wall normal contact forces, Hertzian model and for the tangential contact forces, Mindlin and Deresiewicz model [16] were used. The details and algorithms of contact forces, torsional force calculations and the procedure of intermediate principal stress parameter control are beyond the scope of this paper.

In this study, 4500 particles were generated randomly with five different diameters of 4, 5, 6,7 and $8 \mathrm{~mm}$. The specimen geometry was chosen in a way $[7,17]$ to minimize the effect of non-uniformity. Dimensions of test specimens used for simulations were $200 \mathrm{~mm}$ length hollow cylinders having a $20 \mathrm{~mm}$ thickness, $60 \mathrm{~mm}$ inside and $100 \mathrm{~mm}$ outside diameters. Also, these dimensions were the same as the experimental dimensions [14] used to verify the DEM results. At this study, rigid walls were defined to apply the boundary forces. These walls were defined in plane and cylindrical shapes. The coefficient of friction for both inner and outer cylindrical walls were set to zero to allow the boundary particles freely move in contact with boundaries.
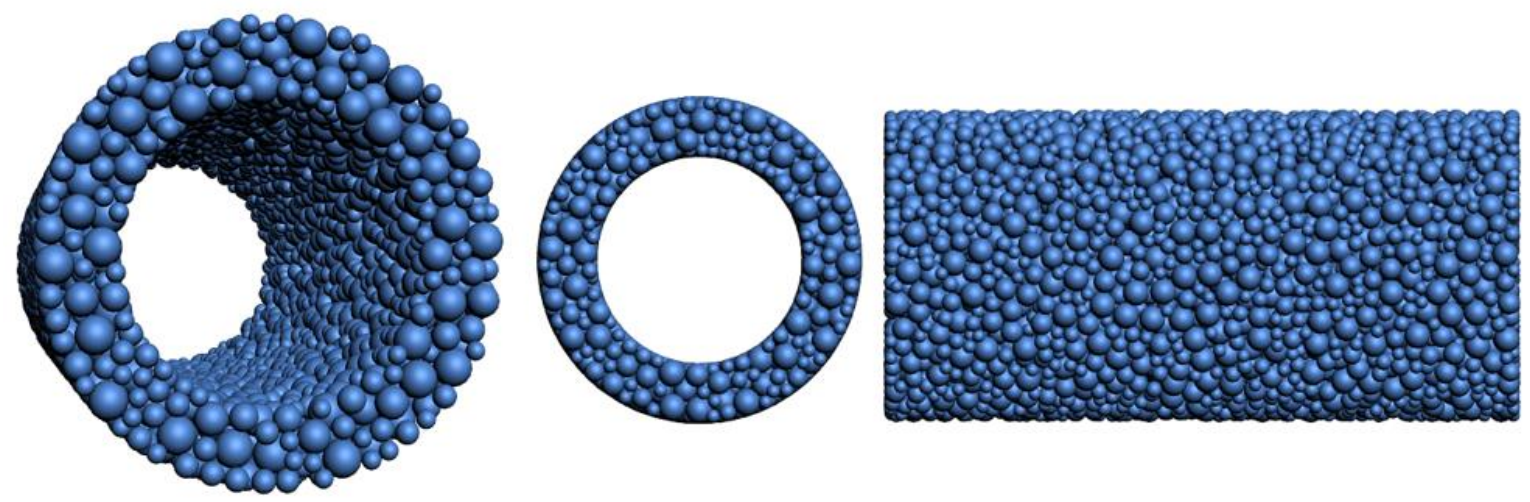

Figure 2: Final model after the isotropic compaction phase and before the deviatoric loading phase

Gravity was set to zero during the entire simulation procedure. Axial force was applied using the upper plane-wall and radial forces were applied using the inner and outer cylindrical walls. Walls can be operated independently from each other and have the ability to move straincontrolled or stress-controlled (servo-control). Also, as previously described, to control the intermediate principal stress parameter (b) while applying the torsion, the inner and outer stresses were dependent to each other. It should be noticed that periodic boundaries cannot be used when using the walls. Figure 2 shows the final model after the isotropic compaction phase and before the deviatoric loading phase. All samples in this stage had an initial void ratio "e" of 0.7 and simulations were carried out as shown in Table 1. 
Table 1: Data table of simulation tests

\begin{tabular}{lccccc}
\hline Parameters & \multicolumn{5}{c}{ Value } \\
\hline Confining Pressure P'0 (KPa) & 200 & 400 & 600 & 800 & 1000 \\
$\alpha\left({ }^{\circ}\right)$ & 0.0 & 15.0 & 30.0 & 45.0 \\
\hline
\end{tabular}

To apply the torque (T), particles which were adjacent to the upper plane wall, were used. The upper plane wall applies the vertical force as well. In deviatoric stress application phase, all walls with the stress servo control mode and a limited velocity, were commenced to move. This limited velocity value is determined by the unbalanced force ratio of particles in the system. A small magnitude of $\xi=10-3$ was shown to be adequate.

\section{VERIFICATION}

To verify the model, the results of experimental hollow cylinder tests on Firoozkooh sand [14] under monotonic loading and drained condition were employed. There are still some limitations in this study such as spherical particles were used for simplicity which could not consider the effects of particle shape. Also the gradation of granular soil and its material properties which is employed in the numerical model, is not the same as used in experiments. Therefore, the results presented here, are compared qualitatively.
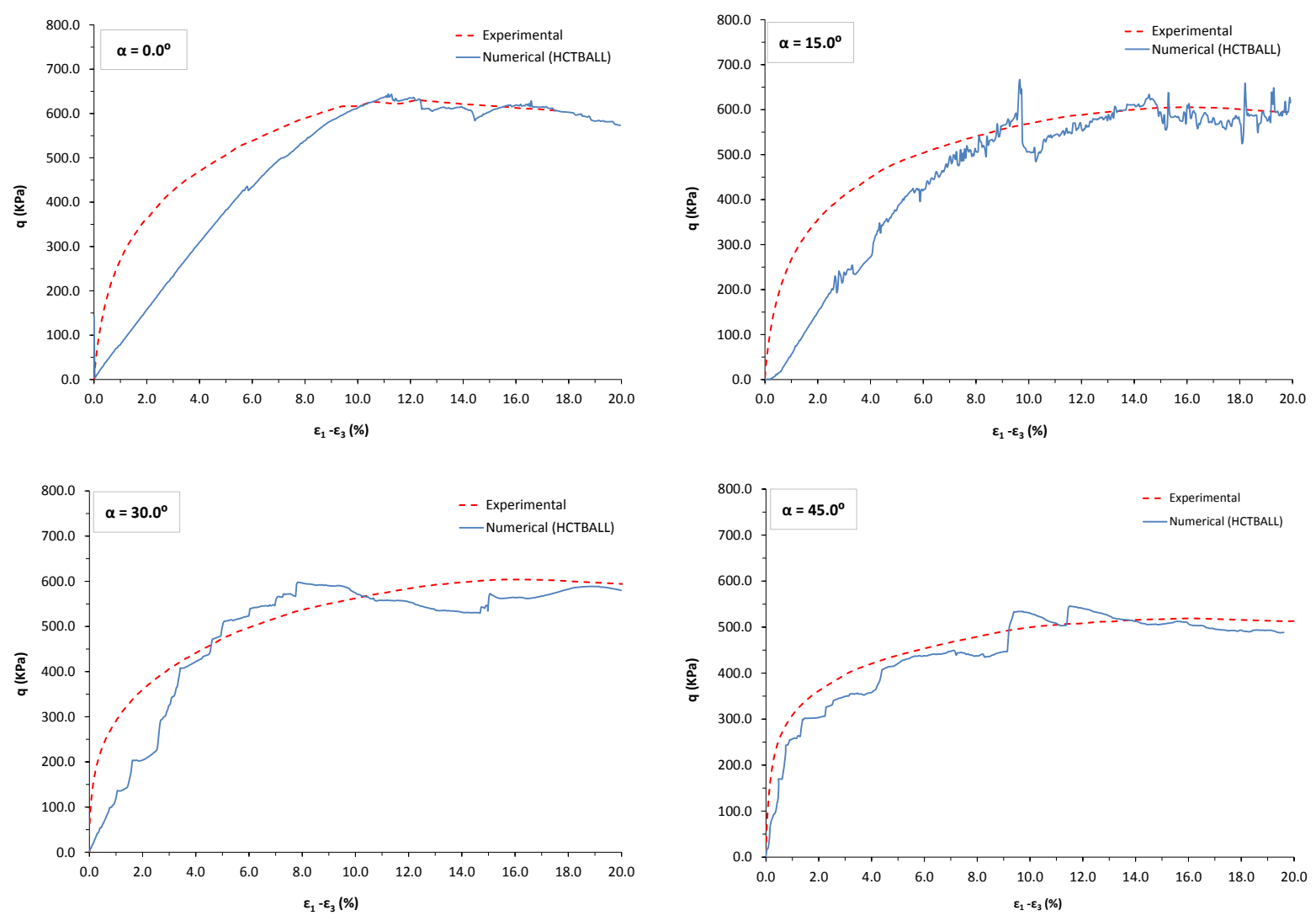

Figure 3: Comparing the experimental and numerical results of deviatoric stress-strain response in a hollow cylinder specimen with $\mathrm{P}^{\prime}{ }_{0}=200 \mathrm{KPa}, \mathrm{b}=0.0$ and different $\alpha$ angles 
Comparing the presented model and experimental results according to Figure 3, it is shown that there was a close association between this model and the experiments. Also, $\alpha$ value was controlled during each test as shown in Figure 4. It is shown that there is a good control of $\alpha$ value in the numerical simulations.

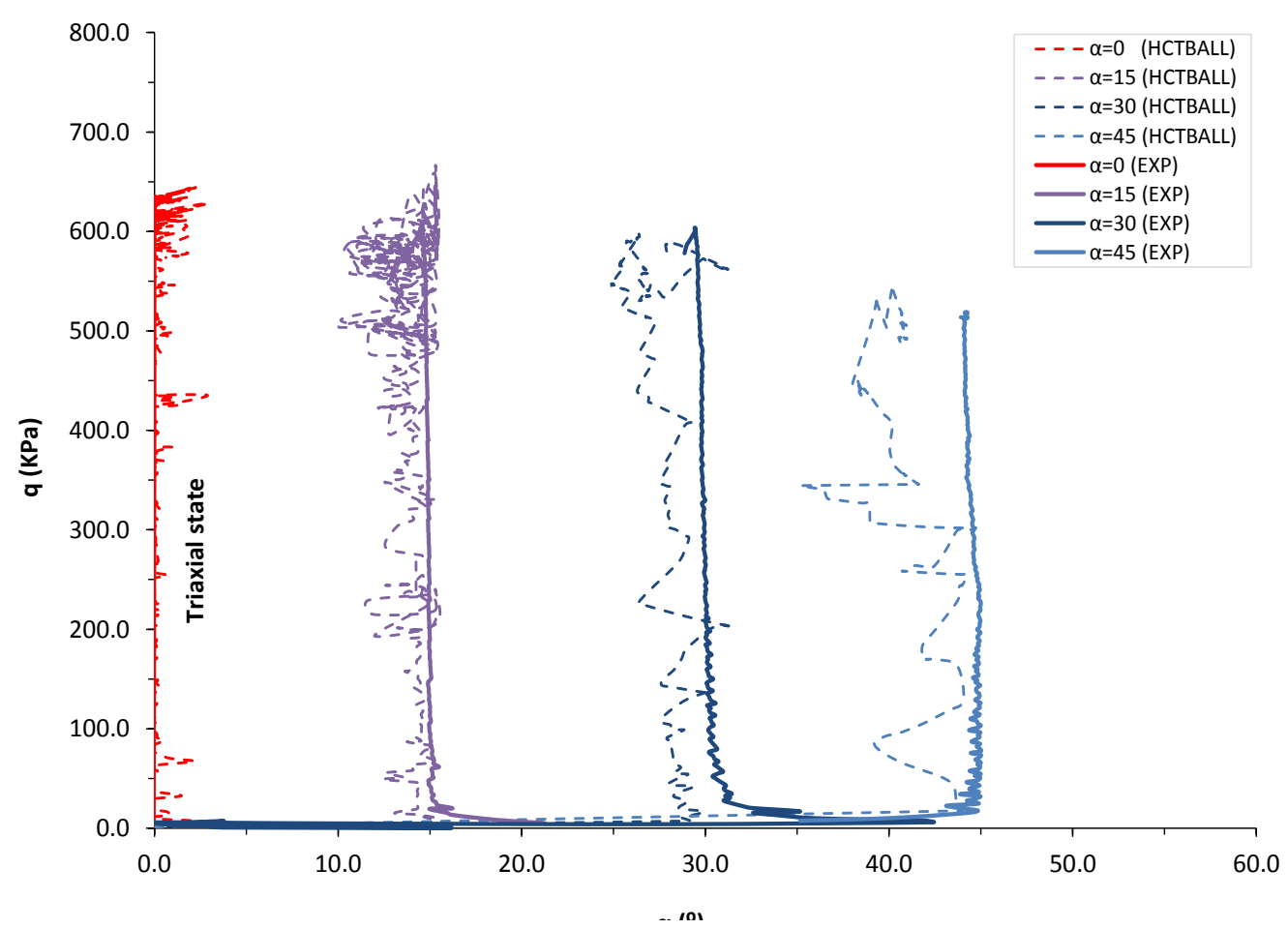

Figure 4: Comparing the experimental and numerical results of deviatoric stresses in a hollow cylinder specimen with different $\alpha$ angles and $\mathrm{P} 0=200 \mathrm{KPa}$

\section{RESULTS}

Numerical results of deviatoric stresses in a hollow cylinder specimen with different confining pressures for different $\alpha$ angles are shown in Figure 5. It is observed that the deviatoric stress increased with a decreasing rate by increasing the confining pressure in different $\alpha$ values. As $\alpha$ was increased, the difference between deviatoric stresses with different confining pressures was decreased. The results of deviatoric stress values are summarized in Table . It is observed that by increasing P'0, the difference between deviatoric stresses, were increased as shown in Figure 6.

Table 2: Deviatoric stress values (q) for numerical simulations

\begin{tabular}{llllll}
\hline & & & & & \\
& & $\alpha=0.0^{\circ}$ & $\alpha=15.0^{\circ}$ & $\alpha=30.0^{\circ}$ & $\alpha=45.0^{\circ}$ \\
\hline $\mathrm{P}_{0}^{\prime}=200$ & $\mathrm{KPa}$ & 574 & 615 & 575 & 488 \\
$\mathrm{P}_{0}=400$ & $\mathrm{KPa}$ & 1153 & 1092 & 836 & 702 \\
$\mathrm{P}_{0}^{\prime}=600$ & $\mathrm{KPa}$ & 1612 & 1492 & 1200 & 898 \\
$\mathrm{P}_{0}=800$ & $\mathrm{KPa}$ & 2113 & 1928 & 1251 & 1182 \\
$\mathrm{P}^{\prime}=1000 \mathrm{KPa}$ & 2599 & 2122 & 1554 & 1427 \\
\hline
\end{tabular}



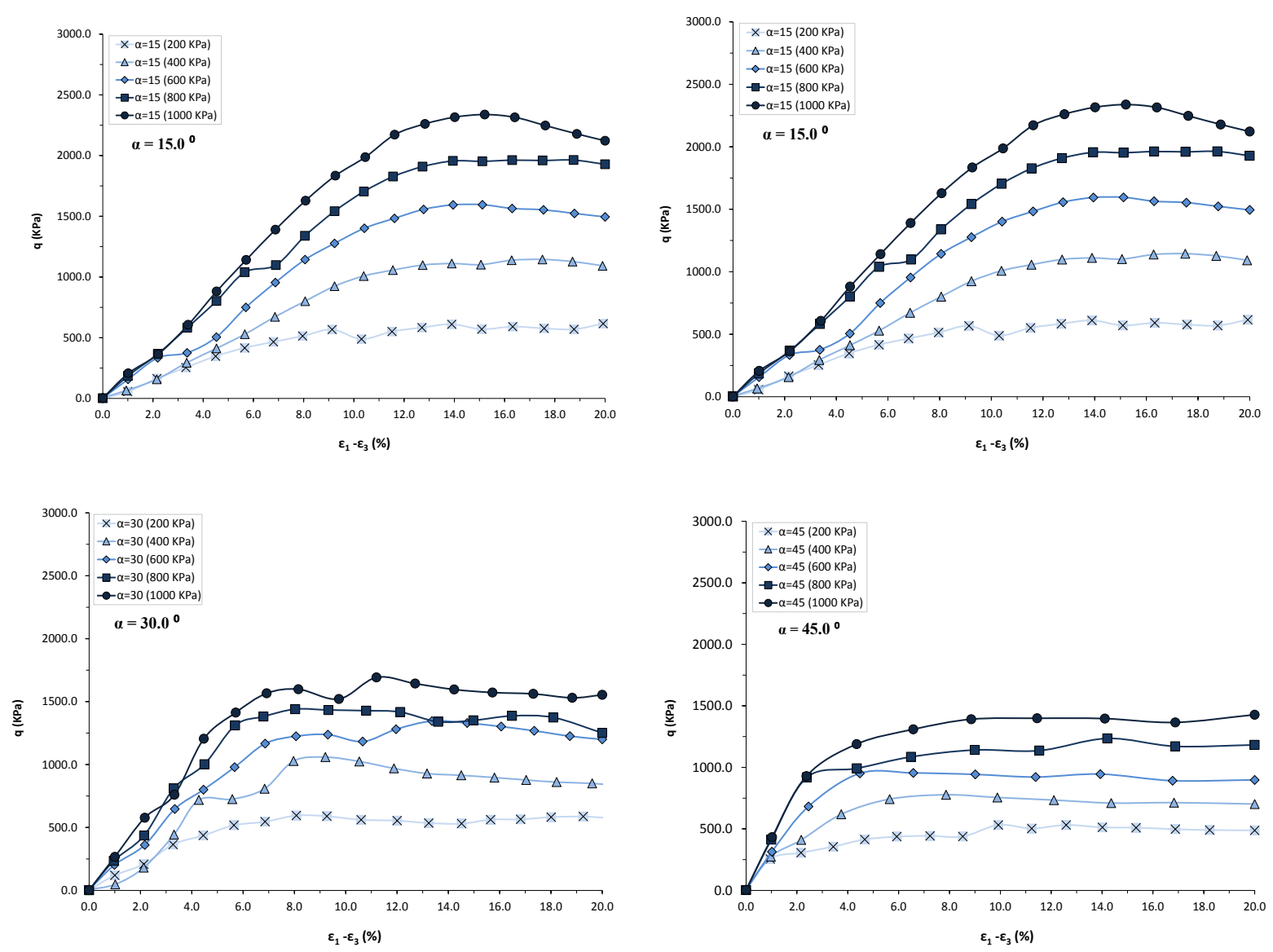

Figure 5: Numerical results of deviatoric stress versus axial strain in a hollow cylinder specimen with different $\mathrm{P}_{0}$ for $\mathrm{b}=0.0$ and $\alpha$ angles of $0.0,15.0,30.0$ and 45.0 degrees

\section{CONCLUSION}

The results reported in this paper, illustrated that the presented numerical model is a proper tool to study the effects of principal stress rotation on granular soils and the stress-strain behavior of granular media was presented.

It was observed that the deviatoric stress at failure, increased with a decreasing rate by increasing the confining pressure. By increasing the rotation angle of principal stress direction, the difference between deviatoric stresses in specific confining pressures was decreased. Moreover by increasing the confining pressure, the difference between deviatoric stresses in specific $\alpha$ values, were increased.

In this paper it was shown that it is possible to obtain the essential features of the mechanical behavior of granular materials under complex stress state by using DEM. 

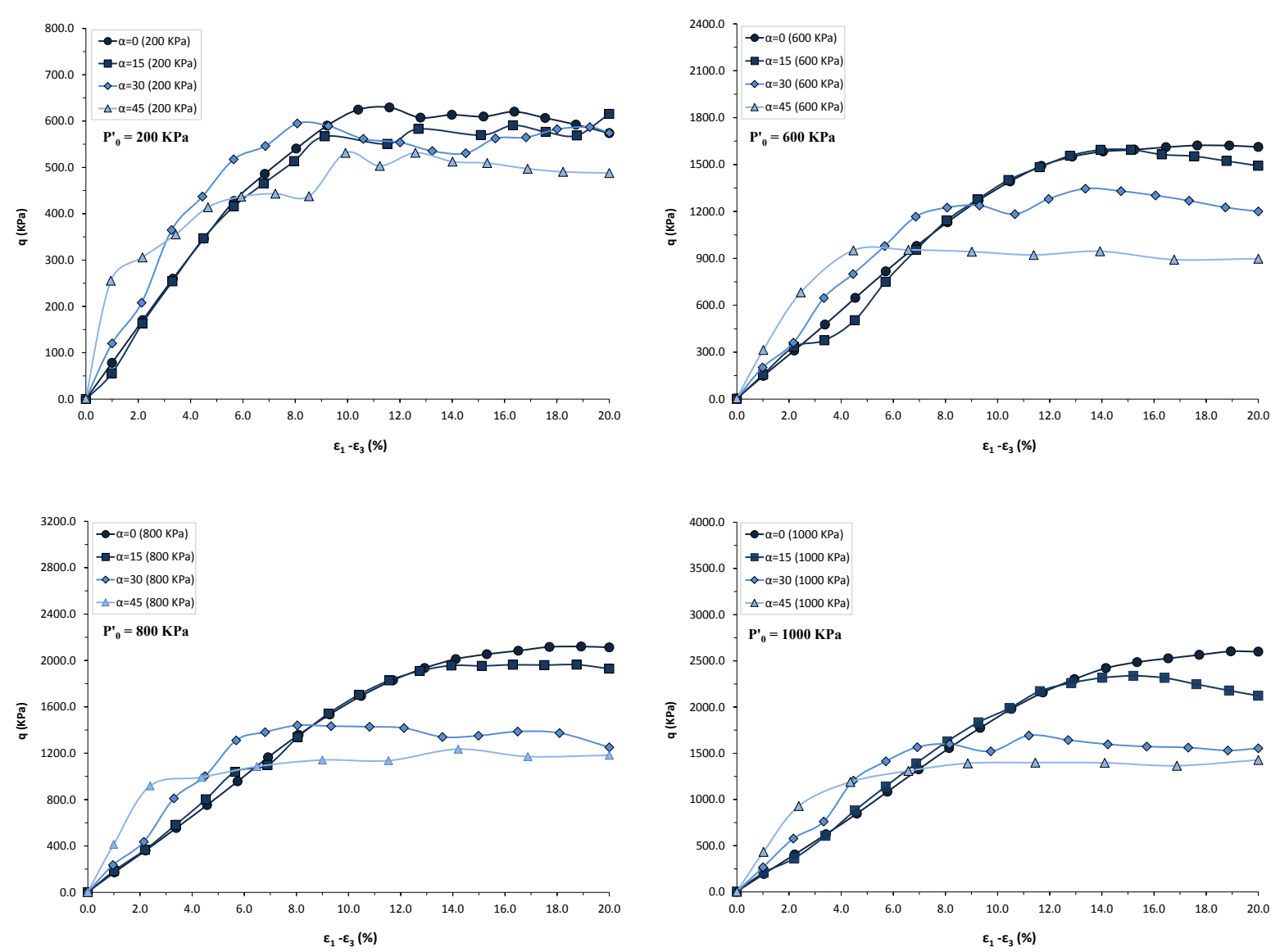

Figure 6: Numerical results of deviatoric stress versus axial strain in a hollow cylinder specimen with different $\alpha$ angles for $\mathrm{P}_{0}$ of $200,600,800$ and $1000 \mathrm{KPa}$

\section{REFERENCES}

[1] Symes MJPR, Gens A, Hight DW. Undrained anisotropy and principal stress rotation in saturated sand. Géotechnique. 1984;34(1):11-27.

[2] Gutierrez M, Ishihara K, Towhata I. FLOW THEORY FOR SAND DURING ROTATION OF PRINCIPAL STRESS DIRECTION. Soils and Foundations. 1991;31(4):121-32.

[3] Saada A, Townsend F. State of the art: laboratory strength testing of soils. Laboratory shear strength of soil, ASTM STP. 1981;740:7-77.

[4] SAADA AS. Hollow cylinder torsional devices: their advantages and limitations. ASTM special technical publication. 1988977):766-95.

[5] Symes M, Gens A, Hight D. Drained principal stress rotation in saturated sand. Geotechnique. 1988;38(1):59-81.

[6] Naughton PJ, O'Kelly BC. Stress non-uniformity in a hollow cylinder torsional sand specimen. Geomechanics and Geoengineering. 2007;2(2):117-22.

[7] Hight DW, Gens A, Symes MJ. The development of a new hollow cylinder apparatus for investigating the effects of principal stress rotation in soils. Géotechnique. 1983;33(4):35583. 
[8] O'Sullivan C. Particle-based discrete element modeling: geomechanics perspective. International Journal of Geomechanics. 2011;11(6):449-64.

[9] Cundall PA. The measurement and analysis of accelerations in rock slopes: Imperial College London (University of London), 1971.

[10] Cundall P. Computer simulations of dense sphere assemblies. Micromechanics of granular materials. 1988;4:113-23.

[11] Dorostkar O, Mirghasemi AA. Micro-mechanical study of stress path and initial conditions in granular materials using DEM. Computational Particle Mechanics. 2015:1-13.

[12] Li B, Zhang F, Gutierrez M. A numerical examination of the hollow cylindrical torsional shear test using DEM. Acta Geotechnica. 2015;10(4):449-67.

[13] Li B, Guo L, Zhang F-s. Macro-micro investigation of granular materials in torsional shear test. Journal of Central South University. 2014;21(7):2950-61.

[14] Romiani HM. Evaluation of Inherent and Induced Anisotropy of Sandy Soils Using Hollow Torsion Apparatus. Tehran - Iran: IUST (Iran University of Science and Technology), 2014.

[15] Yang Z, Li X, Yang J. Undrained anisotropy and rotational shear in granular soil. Geotechnique. 2007;57(4):371-84.

[16] Mindlin RD, Deresiewicz H. Elastic spheres in contact under varying oblique forces. ASME J Appl Mech. 1953;20:327-44.

[17] Sayao A, Vaid Y. A critical assessment of stress nonuniformities in hollow cylinder test specimens. Soils Found. 1991;31(1):60-72. 